\title{
Planejamento da expansão do Setor Elétrico: histórico e perspectivas
}

\section{JOSÉ LUIZ ALQUÉRES}

Engenheiro Civil, Assistente da Diretoria de Planejamento e Engenharia da ELETROBRÁS, membro do Conselho Fiscal da ELETRONORTE, Secretário Executivo do Comitê $\mathrm{Na}$ clonal Brasileirn' da Conferéncia Mundial de Energia.

1. A função planejamento da expansão do Setor Elétrico

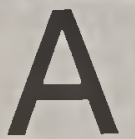
$s$ peculiares caracter ísticas do Setor Elétrico, principaimente a partir do alcance de uma dimensão a nivel nacional expressiva, transformaram, no caso brasileiro, a função planejamento da expansão, numa das mais importantes no contexto empresarial, evidentemente, sem que isso signifique que outras funções devam ser esquecidas.

Destas características, destaca-se a própria velocidade do crescimento do cónsumo de energia elétrica que, nas últimas décadas, vem, por um conjunto de motivos, se expandindo a taxas elevadas, superiores aos $10 \%$ em média por ano. A esse ritmo, observa-se a necessidade de se duplicar as instalaçōes de suprimento a cada 7 anos. Ora, a dimensão fantástica do programa de obras a ser cumprido para facultar essa escala de expansão, evidentemente, realça a necessidade de bem se estudar o elenco de obras a cons. truir, sua adequada distribuição no tempo, etc. Os ganhos empresariais possíveis de serem obtidos, neste campo, através de uma adequada seleção de prioridades, tornam-se, por assim dizer, mais compensadores do que os ganhos importantes (porém menos expressivos), ensejados por uma melhoria na operação dos sistemas existentes.

Um outro fator, importante e peculiar do Brasil, é a abundância de recursos de energia hidráulica. Esses recursos ocorrem em definidas localizações geográficas, não raro distantes dos centros de consumo, implicando o seu aproveitamento na construção de grandes redes de transmissão. Existe, ainda, a propensão de se obter grandes economias de escala na medida do crescimento dessas instalações, principalmente quando, em obras de barragens, é privilegiado, apenas, o aspecto ger ação de energia, como, aliás, tem sido hábito no Setor Elétrico. Assim, o porte dessas obras vem crescen. do ao longo dos anos, fazendo com que - Brasil possua o mais expressivo conjunto de grandes obras prontas, em construção ou projetadas. Se notarmos que o prazo de construção, freqüentemente, supera os 10 anos, verifica-se que o programa de obras em construção, supera, a cada momento, a dimensão global do parque já instalado.

Sob o impacto desse conjunto de fatores, vem se desenvolvendo, principalmente nos últimos 20 anos, a partir da complexidade maior que vem atingindo o sistema elétrico, uma atividade de planejamento muito peculiar às condições brasileiras. Se analisarmos os progressos metodológicos da função planejamento, podemos caracterizar três fases da evolução metodológica, sendo que uma quarta fase se considera, atualmente, em processo, a saber:

Fase 1 - Correspondente ao período até 1963;

Fase 2 - Correspondente ao período compreendido entre 1963 e 1974;

Fase 3 - Correspondente ao período compreendido entre 1974 e 1981/82;

Fase 4 - Período pós 1982.

\section{Fase 1 - Período até 1963}

Neste período, os sistemas elétricos existentes no país eram de pequeno porte, salvo aqueles em torno das cidades do Rio de Janeiro e São Paulo. A responsabilidade pela sua construção e operaçāo cabia a uma multiplicidade de agentes, privados e governamentais, que, embora regulamentados por uma legislação abrangente, desde o Decreto 41.019, de 26.02.57, eram extremamente vulneráveis e políticas fortuitas do poder central. Nos últimos anos dessa fase, proces. sou-se o in ício da formação institucional do Setor Elétrico, com a consolidação de algumas empresas regionais, como CHESF e FURNAS, a criação da ELETROBRÁS, a maturidade e exportação do "modelo CEMIG" a nivel estadual, e a prática de uma postura administrativa, a nivel de Governo, que assegurou às empresas condições adequadas de remuneração de serviços, investimentos e capitalização própria.
Compreendendo, portanto, o Setor Elétrico, um conjunto amplo de sistemas isolados ou, quando muito, com fraco nível de intercâmbio, operados por agentes distintos e, não havendo, sequer, até o final do perfodo, um agente centralizador efetivo a nivel nacional, entende-se que o planejamento da expansão se voltasse a uma ação por projeto.

Com isso, entende-se que, de posse de procedimentos clássicos, as empresas selecionavam entre alternativas a meIhor forma de agregar uma certa expansão na sua capacidade de suprimento, seja a nível de geração, seja a nível de transmissão. Essas expansões se deram, quase sempre, nas suas prórpais áreas de concessão e os sistemas de transmissão representavam redes pouco complexas, ligando, unidirecionalmente, fontes ge. radoras a centros de consumo.

Fase 2 - Período compreendido entre 1963 e 1974

$O$ in ício desse perfodo é marcado pela elaboração de Planos Regionais para as regiōes Sudeste e Centro-Oeste (CANAMB RA) e Região Sul (CANAMBRA), aos quais se seguiram outros para a Região Nordeste (ENENORDE) e a Região Norte (ENERAM).

Em decorrência do crescimento dos mercados e do apontado nesses planos regionais e nos que lhes sucederam, iniciou-se, no período, a interligação entre sistemas a nível intra-regional. As empresas amadureceram nas suas configuraçōes institucionais e o explosivo crescimento da demanda induziu a um fortalecimento do modelo de organização que se mostrava apto a atender ao desa. fio básico do crescimento, onde se des. tacava a ELETROBRÁS, principalmente seu papel de agente financeiro setorial.

Do ponto de vista metodológico, registra-se que, decorrente da tendência para interligaçāo, o planejamento passa a considerar niveis mais elevados do que o de empresa individualizada, como no periodo anterior. A seleção de empreondimentos passou a se fazer dentro de uma ótica mais regional, já que a energia elétrica, cada vez mais, demandava maiores potenciais, em geral mais distantes e, portanto, necessitando, para sua utilização, de transmissāo a longas distâncias. O "próximo empreendimento" 
passou a ser objeto de análises com base no seu benefício para o sistema. A otimização do sistema hidrotérmico, a simulação de "loadflow" nas redes mais complexas de transmissão que iam se formando, e um certo grau de valorização de decisão do poder central (ELETROBRÁSI, são características do planejamento da época, o qual privilegiou o desenvolvimento metodológico com isso compatível.

E de se ressalvar que, até o final desse período, o planejamento do Setor Elétrico ainda era conduzido na total independência em relação a quaisquer outros se tores energéticos e, mais ainda, não existiam planos nacionais. A sistemática de revisões dos planejamentos regionais era suficiente para atender às necessidades objetivas de definição de novos empreendimentos que o crescente mercado demandava.

Fase 3 - Período compreendido entre 1974 e $1981 / 82$

Essa fase é marcada por dois fatores no plano mundial: crise energética, com súbito crescimento do preço do petróleo, e a crise econômica, com uma não me. nos brutal elevação do custo dos recursos financeiros.

O primeiro fator implicou numa cres. cente demanda de divisas para fazer frente à compra de petróleo, para o que, entre outros, o Setor Elétrico foi chamado a comparecer, na forma de captação de financiamentos vinculados à aquisição de equipamentos para alguns projetos então concebidos, por vezes, for a dos esquemas oficiais de planejamento do Setor. Assim, ao se verificar o segundo fator, o Setor se encontrou muito vulnerável, o que se acentuou com a deterioração das tarifas, isto, já por efeito da conjuntura inflacionária interna e a estratégia de reajustes então adotada.

Assistiu-se, do ponto de vista institucional, no periodo, ao fortalecimento da centralizaçåo da gestāo governamental, no contexto do qual o planejamento, a médio e longo prazos, tão valorizado para o Setor Elétrico, foi praticamente abandonado, a troco de uma gestão financeira mais imediatista, decorrente do contexto econômico problemático.

Embora, o processo formal de planejamento do Setor não tenha se interrompido - pelo contrário, registra-se, mesmo, um intenso progresso em métodos e técnicas específicas - sua representatividade caiu bastante. No afả de aumentar essa representatividade, o Setor incorpo- rou ao planejamento toda uma frente de análise de repercussões sobre a indústria de equipamentos e materiais. Por outro lado, a validade do apontado no planejamento do Setor Elétrico veio a sofrer restrições, face a determinações de se adotar, sem crítica, parâmetros fornecidos pela NUCLEBRAS.

Os documentos de planejamento do periodo adquiriram dimensão nacional, como o conjunto de Projetos Especiais da ELETROBRÁS, Plano 95 e Plano 2000 e, também, evoluíram qualitativamente, principalmente, pela disseminação da informática no âmbito do Setor. Registra-se, a propósito, que o Centro de Processamento de Dados da ELE. TROBRÁS só foi implantado em 1973.

Permaneceram esses documentos (embora o último já elaborado com a colaboração de órgãos, tanto do Setor, como externos) como produtos de uma visão centralizadora do processo de planejamento, não havendo comprometimentos externos ao Setor, no tocante à viabilização das premissas consideradas nesses planos.

\section{Fase 4 - Período pós-1982}

A partir de 1982, sistematizou-se, sob a coordenação da ELETROBRÁS e através do GCPS (Grupo Coordenador do Planejamento do Sistema Elétricol, a prá. tica de um planejamento de cunho mais representativo, com a participação das empresas afetadas.

Elabora-se, também, no período, o inficio de uma reação institucional ao centralismo, que, na prática, transferiu todas as decisões essenciais ao Setor, para brgãos e instâncias externas a ele. $\mathrm{Pa}$ ralelamente, o Setor se viu obrigado a valorizar o estudo da parte económicofinanceira de seus projetos de expansão, que deverá se processar num contexto de escassez de recursos, sem precedentes na sua história recente, obrigando, com isso, uma integração planejamento-investimento-recursos financeiros, sem a qual não haverá planejamento efetivo.

\section{As etapas e o ciclo de planejamento no âmbito do Setor Elétrico}

$\mathrm{Na}$ sua forma atual, o processo de planejamento pode ser dividido em três etapas principais: a análise de longo prazo, alcançando um horizonte em torno de 30 anos; a análise de médio prazo, enfocando a evolução do sistema nos primeiros 15 anos, e a análise de curto prazo, definindo os $\mathbf{5}$ anos iniciais.
A análise de longo prazo permite identificar as principais linhas de desenvolvimento do sistema e fixar, em função da composição do parque gerador e da necessidade de desenvolvimento de processos tecnológico-industriais, as metas para o programa de expansão de médio prazo. Nesta fase, os principais insumos necessários são as projeções de mercado, os inventários das fontes de geração, as tecnologias e custos de transmissão e as características do sistema existente. Como principais produtos desta etapa, são obtidos a composição do parque gerador, a seqüência das usinas, os niveis de importação e exportação de energia, a topologia e tecnologia dos grandes troncos de transmissão, os investimentos necessários e, finalmente, os parâmetros energéticos e econômicos.

A análise, a médio prazo, estabelece o programa de expansão, condicionado pelos resultados da análise de longo prazo, que atende aos requisitos previstos, compatibilizando-os com as condiçōes vigentes no Setor Elétrico, bem como com sua evolução. Como primeiro re sultados, são obtidas as alternativas de programas de obras de geração e trans. missão. A partir dessas alternativas, é efetuada uma análise econômica, visando estabelecer o Programa de Expansão do Parque Gerador de Referência. Os estudos de sensibilidade para ajus. tes no programa de geração e de avaliação do desempenho elétrico do sistema de transmissão fornecem os subsídios para a elaboração do Plano Decenal da Geração e Transmissão e, a partir das diretrizes estabelecidas pela ELETROBRÅS, fornecem os elementos para a Programação Plurianual de Investimento do Setor de Energia Elétrica (PPE).

A análise de curto prazo representa um ajuste de decisões referentes ao programa de expansão do parque gerador. um programa detalhado dos reforços da transmissão e a definição do programa de expansão da rede de distribuição. Para o desenvolvimento dessa etapa, são necessárias informaçōes sobre mercado, programa de referência, limites de in. tercâmbio e despachos, restriçōes construtivas e orçamentárias. Além desses insumos, devem estar disponíveis os custos, os índices de confiabilidade e as ca. racterísticas das usinas. Subsidiariamen. te aos estudos do planejamento, a operação dos sistemas aporta, nesta etapa, uma importante contribuição sobre o status operativo do sistema e sua visão de prioridades. 
A expressão financeira do programa de obras é apresentada no PPE, que consiste na programação de investimentos das empresas do Setor de Energia Elétrica. Neste programa são discriminados os principais empreendimentos da empresa, com previsão de investimentos para os 5 primeiros anos, apresentados ano a ano. O Programa de Investimentos é submetido pelas empresas à apreciação da ELETROBRÁS.

A Secretaria de Controle de Empresas Estatais (SEST), no sentido de centralizar o controle de dispêndios das Estatais, estabeleceu o PDG, que consiste na elaboração do orçamento global de dispêndios das empresas estatais. Este programa apresenta uma proposta de orcamento para o ano em curso e informaçōes referentes aos anos subseqüentes, sendo que, na prática, apenas o definido para o primeiro ano acaba prevalecendo após a aprovação da SEST, que o analisa essencialmente pelo seu aspecto financeiro.

Pode-se dizer que, embora comuns a todo o processo de planejamento, as diversas variáveis envolvidas têm pesos diferentes em cada um dos horizontes de planejamento. Assim í que, no longo prazo, os condicionantes estratégicos, ligados à expansão da economia, à disponibilidade de recursos primários e tecnológicos, assumem papel fundamental; no médio prazo, a condiçāo de economicidade dos programas (custos mínimo) é determinante; no curto prazo, a análise financeira e condições como prazos de construção, variações de crescimento dos requisitos de mercado, capacitação empresarial e outras variáveis conjunturais, preponderam.

Por sua vez, os estudos relativos a cada horizonte têm prioridades distintas. A revisão dos estudos de longo prazo, que pressupõem a elaboraç̃o de um plano, só se faz necessária quando de mudanças significativas nos condicionantes estratégicos e nas variáveis macroeconómicas que afetam as diretrizes de longo prazo do Setor Elétrico. Sua periodicidade normal situa-se em torno de cinco anos, quando da elaboração de planos do Governo.

Os estudos de médio prazo são revistos com maior freqüência, função da própria evoluçāo das informações em que se baseiam, como previsões de mercado, evolução dos orçamentos de usinas, etc. e são revistos, normalmente, em intervalos anuais.

Já os estudos de curto prazo, sujeitos a variáveis conjunturais, såo em geral re- vistos várias vezes ao longo do ano, embora, oficialmente, exista apenas um produto anual.

O ciclo de planejamento do Setor Elétrico tem periodicidade anual, e desenvolve-se, continuamente, ao longo do tempo, num processo de elaboração e revisão de metas, frente às flutuações do mercado e outras influências endógenas ou exógenas ao Setor.

A coordenação das atividades de planejamento é exercida pela ELETROBRÁS, por intermédio do Grupo Coordenador de Planejamento dos Sistemas Elétricos (GCPS), e dos seus elementos estruturais, que são o Comitê Diretor (CD), a Secretaria Executiva (SEC), os Comitês Técnicos (CT) e os Grupos de Trabalho (GT).

O processo se inicia com duas informaçōes básicas: a Previsão do Mercado de Energia Elétrica para o decênio que se inicia, emitida pelo Grupo de TrabaIho de Previsão de Mercado (G TPM), do GCPS, e o resultante Programa de Geração de Referência, produzido pela ELETROBRÁS.

O Programa de Geração de Referência é submetido ao GCPS, que através de seus Grupos de Trabalho de Análise do Programa Decenal de Geração (GTPG) e de Sistemas Isolados (GTSI), verifica, face aos dados de mercado, a adequação da programação para entrada das usinas geradoras recoméndada pela ELETROBRĀS. Após referendada pelo Comitê Diretor, constituído por Diretores e Planejamento das Empresas, a programação é assumida como válida para o ciclo de planejamento daquele ano.

O mercado, após aprovado pelo Comitê Diretor, é encaminhado ao Subgrupo de Estudos de Mercado dos Principais Centros de Carga (SGPC) e ao Grupo de Trabalho do Plano Decenal de Transmissăo (GTPD), sendo entăo produzido por este último o Plano Decenal de Transmissão, que norteará as empresas em seu planejamento de obras para o próximo decênio.

Com as informações referentes às obras de geração e transmissão, as empresas elaboram seus PPE's (Programa Plurianal de Investimentosl, enviando-os à ELETROBRĀS para serem analisados. A ELETROBRÃS completa a análise do PPE, em todos os seus aspectos técnicoeconômicos, indicando as diretrizes finais para o PDG (Programa de Dispêndios Globais), possibilitando às empresas a consolidação dos seus valores e considerando as restrições existentes. A ELE. TROBRAS, em seguida, se responsabiliza pelo envio à SEPLAN do PDG das suas controladas, ao mesmo tempo em que as empresas coligadas estaduais encaminham ao mesmo órgão seus PDG's individuais, que devem estar previamente compatibilizados ao programa global estabelecido.

Os niveis finais de investimento emitidos pela SEPLAN, com base na análise financeira do Setor e em parâmetros de alocação inter-setorial de recursos, não raro inviabilizam totalmente as proposicões encaminhadas, processando-se entåo as adaptaçōes possíveis ao longo do ano, quase sempre implicando em grandes prejuízos à qualidade dos serviços prestados pelo Setor.

No âmbito interno às empresas concessionárias, desenvolvem-se ciclos anuais de planejamento que, nas épocas devidas, se inter-relacionam com o mencionado ciclo de planejamento do Setor Elétrico. É de se destacar nesse âmbito empresarial a importância do seu planejamento integrado. Para a empresa, este define as metas, planos de ação, orçamento de custeio, orçamento de investimento, quadro de pessoal, plano diretor de informática, planejamento setorial e outros instrumentos setoriais, com base em prioridades e diretrizes pré-estabelecidas.

As mudanças no processo de desen. volvimento econòmico e social do pals são fatores que orientam a fixação de prioridades e diretrizes da expansão do sistema elétrico, sendo deste modo determinantes do planejamento. Devido à caracteristica de interdependência sistêmica do planejamento, não poderão ser efetuadas modificaçōes isoladas nos seus componentes sem que todo o processo seja afetado.

Por fim, ressalta-se que a necessidade de uma tradução do planejamento setorial num documento de trânsito mais amplo a nível político - institucional, resultou na criação de Planos Estaduais. Os Planos Estaduais, ou de Territórios Federais, foram criados em 1984, por iniciativa da ELETROBRÁS. Eles são instituldos por Portarias do DNAEE e sua execuçāo compete a Grupos de Trabalho coordenados pela ELETROBRÁS. Estes planos evidenciam os aspectos de planejamento a nivel de unidade da federação, tratados de forma mais abrangente nos documentos de planejamento tradicionais do setor, como, por exemplo, "Plano Decenalde Geração" e "Plano Decenal de Transmissão". Eles visam, portanto, identificar os requisitos de energia, apresentar os projetos neces. 
Sários para atendimento desses requisitos, caracterizar os estudos e investimentos correspondentes e atribuir as responsabilidades para sua execução.

O Plano Estadual agrega, ainda, um objetivo polftico aos elementos preparados nos fóruns técnicos do Grupo Coordenador do Planejamento do Sistema Elétrico (GCPS), de forma a torná-lo a expressão da política de desenvolvimento da utilização de energia elétrica empreendida pelo Governo do Estado, face à necessidade de sua compatibilização com a atuação do Governo Federal, através das empresas concessionárias regionais e outros órgãos.

\section{Planejamen to e metodologia: grandes temas}

O planejamento do Setor Elétrico é exercido num contexto onde a experiência demonstra que, a cada época, o peso de diferentes fatores políticos, econômicos ou sociais, produz feiçōes peculiares na sua forma e no seu conteúdo. Assim, no passado, épocas como a de "reconstrução decorrente do realismo tarifário" e "expansão decorrente do milagre brasileiro", imprimiram às dife. rentes decisões, no âmbito do Setor, a sua marca e o seu sentido.

No sentido de bem caracterizar a situação atual do Setor, não se poderia excluir uma colocação, ainda que subjetiva, dos temas que, na metade desta década, condicionam fundamentalmente o planejamento setorial: superação da crise e retomada do desenvolvimento, papel da energia elétrica no contexto da onergia global, meio-ambiente, no seu sentido social e ecológico, recursos hidricos e aproveitamentos hidrelátricos, e configuração polftico-institucional.

\section{Superação da Crise e Retomada do Desenvolvimento}

O Setor Elétrico atravessa uma situa. căo extremamente grave do ponto de vista econômico e financeiro. Sua vulnerabilidade atual é, por conseguinte, bastante grande, pois, de uma rela tiva autonomia financeira, para conduçāo do seu programa de investimentos, veio a cair em grande dependência de recursos externos ao Setor Elétrico. Esse fato enfraquece a efetividade recomendada no seu planejamento.

No panorama atual da economia brasileira, onde o grande problema que se coloca é a retomada do crescimento que assegure a plena utilização dos fato- res de produção e a absorção de mão-deobra, a problemática do Setor Elétrico, pelas suas caracter ísticas, mostra-se agravada. Tradicionalmente, um setor capital intensivo como o Elétrico, no contexto de escassez total de recursos em que vivemos, só consegue reequacionar satisfatoriamente o seu desenvolvimento com mudanças na forma e no ritmo de capitalização. Novas políticas com relação ao atendimento ao mercado, novas formas de conduzir os empreendimentos, novas fontes nacionais ou internacionais de recursos, novos modelos de estruturação empresarial, merecerão ser estudados e eventualmente implantados, de modo que se assegure, compativelmente com as possibilidades nacionais, um reenquadramento do Setor Elétrico num padrão de equilíbrio que, no pas. sado, pôde ostentar.

Papel da Energia Elétrica no Contex. to de Outras Formas de Energia.

Os bens e serviços produzidos pela sociedade exercem uma demanda global de energia. Dentro dessa demanda global, a especificação do uso desta ou daquela forma ou fonte particular de energia vai depender de um certo número de fatores: a disponibilidade física do energético, seja obtido localmente ou através de intercâmbio; os preços relativos das diversas formas ou fontes de energia, para um dado nível de tecnologia de produção e de uso; finalmente, de diversos aspectos - muitas vezes não computados monetariamente de forma direta - que se podem traduzir pelas idéias de conveniência no seu uso, tais como: facilidade de manipulação, grau de lim. peza, exigências de espaço para armazenamento, etc.

A curto prazo, as diversas formas de energia apresentam padrões bastante definidos e estáveis de utilização, tendo cada uma dessas formas seus tipos de consumidores e usos finais relativamente cativos. Ou seja, a intersubstituição entre fontes é relativamente difícil a curto prazo, porque, por um lado, os fatores dos quais dependem o uso (preços, tecnologias disponíveis, etc.), numa perspectiva de curto e médio prazos, são relativamente estáveis, e também porque os serviços de produção de energia, dadas as suas características tecnológicas e de mercado, requerem, na maior parte dos casos, investimentos de grande monta em capital fixo.

Os últimos dez anos viram a quebra da estabilidade do preço do petróleo, exatamente o energético que, ao longo do último meio século, vinha paulatinamente absorvendo o mercado dos demais energéticos e transformando-se nu. ma espécie de alternativa monoenergética e universal, através do efeito conjugado de baixo preço, facilidade de intercâmbio e abundância de tecnologias simples para sua utilização. Com á quebra da estabilidade dos preços do petróleo, reverte-se a tendência à ampliação de seu uso, passando a viver o mercado global de energia enorme grau de incerteza quanto à definição do papel das demais fontes, no atendimento das crescentes necessidades globais por energéticos.

No caso brasileiro, como resultado da alta dos preços do petróleo, adotou-se uma política deliberada de procura de alternativas energéticas e passa-se por uma certa euforia na substituição de derivados, que, se nem sempre é ditada pela razão, por outro lado, sequer atinge seus objetivos especificados. Nesta fase, vários energéticos se apresentam com a suposta capacidade para substituição efetiva e virtual dos derivados de petróleo, dentre eles, a eletricidade. Esta capacidade, no entanto, nem sempre veio acompanhada pelo requisito básico da disponibilidade de tecnologia de uso, a preço-sombra competitivo.

O Setor Elétrico tem interesse particular, dado o gigantismo dos investimen. tos que requer, em definir com rigor a posição da eletricidade, face aos demais energéticos, neste quadro de incerteza que caracteriza o mercado global de energia. Por outro lado, a natureza unificada do planejamento e da administra. ção de preços do Setor Elétrico possibilita, melhor do que em outros merca. dos de energéticos, esta definição que, em última instância, vai delimitar mercados, esquivando-se a eletricidade de absorver os mercados nos quais outros energéticos possam vir a cumprir mais adequadamente o seu papel final (entre eles os próprios derivados de petróleo) e, por outro lado, absorvendo resolutamente aqueles novos mercados onde tecnologias e preços lhes forem favoráveis. Esta definição requer, naturalmente, estudos cuidadosos das potencialidades de novos usos finais para energia elétrica, via-à-vis outros energéticos, tradução desta potencialidade em requisitos de mercado e, finalmente, na inserção destes requisitos no planejamento da oferta do Setor.

Finalmente, deve-se ter em-mente que, não só as novas tecnologias de pro. dução, como também aquelas ligadas 
aos usos finais, modificam significativamente a competitividade entre energéticos. Neste caso, cabe ao Setor Elétrico investir na geração de tecnologias de uso que possam vir a facilitar à eletricidade a absorção de novos mercados, cujo uso, por motivos de preços, conveniência, etc. mostram-se desinteressantes no momento. Parte deste esforço de geração de tecnologia deve, tambám, visar a obtenção de níveis maiores de eficiên. cia no uso da energia elétrica, o que permitirá a extensão dos recursos existen. tes por horizontes temporais cada vez mais longos.

\section{Meio-Ambiente e Implicaçð̃es Sociais}

A conservação dos recursos naturais e o desenvolvimento económico e social, são apresentados, na maior parte das vezes, como sendo incompatíveis. É necessária, pois, a compatibilização entre a ecologia e o desenvolvimento econômico e social, obtida através da aplicação de novas tecnologias oriundas do desenvolvimento científico.

A harmonização do binômio tecno. logia-ecologia é um dos desafios mais sérios que a humanidade enfrenta nos tempos atuais. Considerando que o desevolvimento cientifico é uma conquista do homem, cuja aplicação tecnológica deve se adequar às condições ecológicas, conclui-se que a unilateralidade da tecnologia não é a correta visão do futuro, assim como não é absoluto o imediatismo da relação benefício/custo. Deve ser destacado que o caráter público das em. presas estatais exige critério de avaliação que transcenda os conceitos clássicos de lucratividade e rentabilidade econômica, para incluir critérios valorativos de sua contribuição para o progresso económico, social e polftico do pals.

$\mathrm{Na}$ construção de sistemas elétricos, a implantação de reservatórios de usinas hidrelétricas, de linhas de transmissão e subestações, introduzem importantes modificaçōes ambientais com a alteraçåo do meio f/sico, biótico, social, económico e cultural das áreas afetadas. Embora em menor escala, no caso brasileiro, as instalações de usinas termelétricas introduzem, também, modificações no meio-ambiente. Por outro lado, os sistemas elétricos são influenciados pelo meio-ambiente, sofrendo restrições, não só do ambiente natural, mas, também, de quase todas as atividades econômicas desenvolvidas pelo homem. Objetivando minimizar estes efeitos negativos, såo necessários estudos e medidas de con- trole ambiental e o aproveitamento das áreas onde serão instalados os sistemas elétricos.

O Setor de Energia Elétrica, consciente dos benefícios, inclusive os de uso múltiplo, e das modificações introduzidas no meio-ambiente, pela cons. trução de sistemas elétricos, desenvolveu um "Manual de Estudos dos Efeitos Ambientais dos Sistemas Elétricos", apresentando um conjunto de procedimentos e estudos que devem acompanhar todas as etapas que visem a implantação dos sistemas elétricos, desde o planejamento até a sua operação, de modo a estabelecer diretrizes que possam conciliar o desenvolvimento econômico $\theta$ social e a conservação dos recursos naturais.

Neste sentido, será necessária que a intervenção que se pretende no meioambiente com a construção de sistemas elétricos seja criteriosa, de modo a minimizar os impactos previstos. Atenção deve ser dada também aos efeitos ambientais nas instalações projetadas, de modo a se lhes prover a maior vida útil possível. O projeto de sistemas elétricos deve ser precedido de estudos ambientais que permitam avaliar o impacto causado. Estes estudos implicam em planos de levantamento ambiental da área afetada e na adoção, nos projetos de engenharia, de medidas que minimizem os efeitos causados nas instalaçőes.

Todas essas questões, sem dúvida alguma, se constituirão em grandes temas para a década de 80 , havendo, portanto, a necessidade de incorporar 0 enfoque energético-ambiental na metodologia de planejamento de sistemas elétricos.

\section{Recursos Hidricos e Aproveitamen- tos Hidrelétricos}

Até a presente data, a maioria das barragens existentes e em construção, foram projetadas com vistas a atender um único objetivo ou, no máximo, considerar de forma completamentar outras finalidades, tais como, abastecimento de água, controle de cheias, irrigação ou regularização de vazões.

Em decorrência do grau de industrialização, urbanização e agricultura inten. siva, atingida pelo paŕs, paralelamente ao descontrolado aproveitamento das águas, estão sendo desericadeados cres. centes conflitos de interesses e que tendem, inclusive, a comprometer o desenvolvimento econômico e social, uma vez que tornar-se-ão escassos os recursos hídricos necessários para atender aos requisitos de quantidade e qualidade da água, o que torna evidente a necessidade de aproveitamento de recursos hídricos, considerando-se os usos múltiplos.

O Comitê Especial de Bacias Hidrográficas, instituído sob a inspiração dos bons resultados alcançados com a gestão dos recursos hídricos da Região Metropolitana de São Paulo, deverá proporcionar os meios necessários para que seja aprimorado o gerenciamento dos recursos hidricos das bacias hidrográficas brasileiras. Como conseqüência, haverá necessidade de se incorporar, no planejamento de aproveitamentos hidrelétricos, o enfoque de usos múltiplos, inclusive os critérios de repartição dos benefícios e custos dos reservatórios entre os diferentes usuários da água.

Um aspecto que deverá merecer, também, uma atenção especial, se refere a critérios de avaliação de terras a serem inundadas pelos reservatórios, pois, do ponto de vista econômico e social mais amplo, essas terras deverão ser avaliadas em função das suas potencialidades econômicas.

Estes fatores levarão a uma tendência de se situar o planejamento da expansão da geração de energia elétrica de fonte hidráulica num contexto, não somente setorial, porém, fundamentalmente regional, analisando-se os aproveitamentos como açōes dentro de um quadro de promoção econômica e social consideravelmente mais amplo que o atual.

\section{Sistema Polltica mais Aberto}

No contexto de uma sociedade politicamente mais aberta, caberá ao Setor Elétrico reformular suas atitudes e procedimentos, em relação à participação mais ampla da sociedade no processo de planejamento. Nessa perspectiva, é inevitável uma politizaçăo crescente do processo de planejamento, caso esse pretenda ser efetivo a nivel dos processos decisórios.

O primeiro nivel de politização ocorre no próprio âmbito do Setor, entre ELETROBRẢS e empresas concessionárias, reforçando fóruns pré-existentes, como o GCPS, num papel de coordena dor dos planejamentos de âmbitos geográficos distintos.

Um segundo nivel de politização refere-se às posturas das empresas com relação a grupos organizados, que questionam programas e projetos que venham, de alguma forma, afetar a vida 
das comunidades, quer em relação ao social, quer com respeito a possiveis danos aos ecosistemas.

Existe, ainda, um terceiro nivel de politização, que poderá ocorrer em virtude do crescente envolvimento dos empregados na gestão das empresas e no apoio oficial à polfticas de co-gestão.

Neste contexto, os órgãos governamentais e as empresas do Setor, terão que trilhar o caminho de fazer do planejamento dos sistemas elétricos uma atividade mais aberta. Os planos e grandes projetos deverão ser comunicados, em suas grandes linhas, aos setores políticos, empresariais e da comunidade, num processo que se mostrará não somente necessário mas desejável.

As entidades do Setor, em seus diversos níveis, sentirão, portanto, a necessidade de se estruturar para este no. vo tipo de inter-relacionamento com a sociedade. Precisarão formular políticas e estratégias para lidar com as situacões que surgirão. Ao mesmo tempo, deverāo se preparar funcionalmente. dentro dos seus organogramas, com o objetivo de atuar de maneira eficaz neste sensível campo em que se fará crescente a influência da sociedade sobre o futuro do setor.

\section{Conclusões}

Numa apreciação global, a metodologia de planejamento do Setor Elétrico vem respondendo às necessidades do Setor. A nível do seu conteúdo técnico. a metodologia progrediu em áreas especializadas, compativelmente com o que de melhor se produz a nivel interna. cional, embora permaneçam existindo desafios para o desenvolvimento pleno de uma metodologia adequada a itodos os aspectos da realidade nacional.

As razōes básicas para o que se apon. ta prendem-se à própria história e evolução do Setor Elétrico no Brasil, que, apenas muito recentemente, criou condiçōes de uma continuidade de funcionamento das atividades de planejamento. É importante ressaltar que, para um Setor saudável tecnicamente e, também, no plano econômico e financeiro, é fundamental a manutenção de quadros técnicos motivados e engajados na criação de métodos nacionais, não só na área do planejamento, como, também, em suas outras especialidades.

As principais recomendaçð̃es e proposições que, em linhas gerais, vem sendo sugeridas, no âmbito do Setor Elétrico, foram agrupadas segundo a sua natureza e estão indicadas nos itens seguintes.

\section{Processo de Planejamento}

A primeira qualidade do processo de planejamento deve ser o seu senso de oportunidade. Os produtos demandados pelos centros decisórios devem estar disponfiveis a tempo de poder subsidiar as decisões e não, como tantas vezes no passado, para se preparar planos e rela. tórios justificando decisões já tomadas. Para isso, e fundamental que o primeiro sentido prospectivo a se desenvolver seja o das decisões estratégicas. Talvez a nossa história fosse outra, caso o planejamento tivesse melhor estudado e divulgado, junto aos setores competentes, assuntos como o papel das usinas nuclea. res, a avaliação do inventário hidroelétrico do Pals, a viabilidade da transmissão a longa distância, etc.

Outro ponto importante, a nível de processo, é a clareza dos documentos de planejamento. Nesse aspecto, o futuro será ainda bem mais exigente, já que, no passado, os documentos eram unicamente voltados para uso interno ao Setor. Pretendendo atingir, doravante, os cen. tros efetivos de tomada de decisão, o planejamento será obrigado a uma clara comunicação e justificação de suas proposições a públicos não especializados e aos segmentos da classe política que, inevitavelmente, se dividirão entre o apoio e a contestação das suas proposiçóes. A título de exemplo, acredita-se que a viabilização de novos aproveitamentos hidrelétricos na Regiào Sul so. mente se tornará efetiva após intensas discussões, a nível de comunidades afetadas e mesmo do grande público, que deverá receber um aporte claro e preci. so sobre a necessidade do proposto pelo planejamento.

Por fim, o processo deverá prosseguir na tendência participativa já posta em prática, o que fará da ELETROBRÁS uma coordenadora do planejamento dos diferentes agentes internos ao Setor e uma intermediadora deste com outros setores de governo. Os planos feitos cen. tralizadamente e de responsabilidade única de uma entidade (ainda que consultadas outras) deverão ceder lugar a documentos elaborados segundo processos mais representativos. É de se lembrar que este fato, certamente, introduzirá uma maior lentidão no proces. so a ser compensado por uma menor necessidade de revisōes e pela identificação mais cedo da oportunidade de elaboração de cada um dos produtos específicos, de forma a se dispor do tempo necessário para o seu desenvol. vimento.

\section{Amplitude do Planejamento}

O escopo clássico do planejamento da expansão do Setor Elétrico esteve voltado à busca das soluçõés ótimas pelo lado da programação das instalações de suprimento, portanto, pela otimização da oferta. Parece não restar dúvida, hoje em dia, que a primeira variável a ser trabalhada adequadamente e, com base num aprofundamento do conhecimento da própria visão econômica do consumo de energia elétrica, seja o mercado.

Possibilidades significativas, a nivel de conservação de energia, poderão permitir ao Setor superar o perfodo mais crítico de ajustamento financeiro que $s$ antevê. Por outro lado, a consideração de mercados, independente do nível de preço do energético, não mais se mostrará adequada, face inclusive ao atual estágio já atingido na cobertura horizontal dos serviços de eletricidade.

$\mathrm{Na}$ área de planejamento da oferta, deverão ocorrer algumas alteraçōes nas metodologias, devido à necessidade de incorporar a variável ambiental, bem como o enfoque do aproveitamento de recursos hidricos, com finalidades múltiplas.

\section{Conteúdo Social}

Alguns aspectos merecem ser considerados, para que venham a inflenciar a metodologia de planejamento.

Já se"mencionou, ao longo do texto, que a metodologia de planejamento da expansão, sempre procurou a otimizacão de um processo de crescimento de um parque de instalações de suprimento, visado sempre sob a b́tica de um crescimento tentacular. A esta lógica de. ve-se contrapor outra, que pode ser denominada abordagem geográfica. Considerando-se a necessidade, em decorrência de uma política de desenvolvimento regional, de se prover energia elétrica à população, a programação de expansão do Setor olhará, não só a expansão de linhas e de mercados interligados, mas todos os vazios ainda não atendidos, para os quais se imporão técnicas especia is de suprimento. Recentemente, a ELETROBRAS, em conjunto com diversas entidades, preparou um manual de seleção entre alternativas de suprimento para sis- 
temas isolados, documento que vem preencher uma lacuna no que diz respeito ao equacionamento do suprimento aos sistemas isolados do Norte e Centro-Oeste brasileiro.

Outro aspecto a ser introduzido na metodologia é o cômputo dos diversos custos sociais, decorrentes da implantação das instalações de suprimento. São bem conhecidos os questionamentos dos ecologistas mais voltados à proteção absoluta da natureza. Ao lado destes, a nível até mesmo do interior das áreas urbanas, são múltiplos os custos sociais incorridos pela população, via deterioração das condições de vida, diminuição dos valores das propriedades vizinhas à instalaçōes de suprimento, perturbação do funcionamento das atividades urbanas ao longo de períodos de construção. aumento de riscos nas vizinhanças de instalações de suprimento (não só nas usinas nucleares), etc., custos estes, decididamente, jamais computados na selecão econômica entre alternativas.

A nível do conteúdo social do planejamento, não se poderá abstrair de aná. lises mais profundas de fenômenos de consumo de energia elétrica à luz das formas de vida, hábitos de consumo e modificação das condiçōes culturais vigentes na sociedade. O Brasil representa um caso muito complexo, pelas dicotomias que apresenta entre os diferentes segmentos sociais e econômicos: socie. dade economicamente modernizada, versus sociedade arcaica; concentraçð̌es de riqueza, versus grandes bolsōes de po. breza; penetração indistinta dos meios de comunicação de massa hoje e, no futuro, talvez, da informática aplicada. Os estudos de balizamento da demanda futura de energia elétrica passaram ao largo deste tipo de problemática, pois, quase sempre, se caracterizaram pela ex. trapolação das tendèncias do passado. 0 que ora se questiona é, até que ponto a prática deste tipo de planejamento acaba ajudando a manutenção do status quo, retirando qualquer componente "normativo" do planejamento. Real. camos, portanto, no momento, a necessidade de se considerar, antecipadamente às formulações de programas específicos por parte do Governo, que mudancas búsicas em alguns parâmetros poderảo decorrer de imposições de ordem social, citando-se, como exemplo, a redução do nível de apropriação da poupança nacional para aplicação no Setor Elétrico, face outras prioridades.

\section{Conteúdo Econômico}

$\mathrm{O}$ aspecto mais premente, a nivel metodológico neste setor, se prende à necessidade do equacionamento da iteração, que se prenuncia inevitável, entre o programa requerido pelo mercado, a constatação de um quadro insuficiente de recursos para atendê-lo e o desenvol. vimento de um programa alternativo, compatível com os recursos. Esse processo, sem dúvida, se repetirá algumas vezes, até uma melhor aferição dos instrumentos de planejamento e, a cada momento, a caracterização de quem não será atendido a contento, será determinante para a formulação dos planos. To. da a metodologia de custo-benefício aplicada ao Setor Elétrico (inclusive com os seus custos sociais, conforme já referidos), deverá se tornar operacional e de rápida manipulação. Ao minimo econômico se acrescentará, portanto, a imposição metodológica dos programas de expansão que se referirem à maximização do benefício social.

\section{Conteúdo Tecrológico}

Ao longo do histórico do planeja. mento, observa-se que o horizonte do seu alcance dilata-se progressivamente. A esta dilatação, deve corresponder um tratamento diferenciado dos componentes tecnológicos e de engenharia, passando a considerar as perspectivas de desen. volvimento tecnológico esperados e, também, a possível variação dos custos unitários das diferentes soluções técnicas de suprimento.

Este fato transforma o planejamento. Este, se por um lado já passava a incorporar toda uma investigação sobre futuros possíveis, à luz de mudanças nas relações econômicas e sociais estabelecidas no passado, deverá, também, considerar a importante variável tecnologia, principalmente no segmento de longo prazo.

Os métodos de avaliação de tecnolo. gias, em fase inicial de desenvolvimento hoje, tendo em vista a sua utilização dentro de 20 anos no Setor, são qualitativamente diferentes a tudo o que se tem trabalhado habitualmente, demandando quadro de pessoal com formaçāo científica e tecnológica diferente.

Cabe, ainda, complementarmente, ao Setor Elétrico, na sua área de competên. cia, produzir e suportar uma política científica de pesquisa e tecnologia, que assegure uma adequada competência nacional nesta área vital para o desenvolvimento.
Inserç̄o no Processo de Planejamen. to a Nivel Global

Os dois níveis naturais de inserção a considerar, dentro da sistemática de planejamento governamental vigente, correspondem ao planejamento do Setor Energé tico de responsabilidade do MME, e o planejamento global macroeconómico, de responsabilidade da SEPLAN.

Nos últimos anos, o planejamento sètorial trabalhou predominantemente com cenários normativos, definindo metas a atingir (de auto-suficiência ener gética, de número de barris de petróleo a substituir por energia elétrica, de quantidade de carvão ou de petróleo a produzir, etc.) e induzindo os diferentes setores à realização de programas compatíveis com essas metas (embora, sem que os meios para tal pudessem se considerar assequrados).

$\mathrm{Na}$ medida em que forem desenvolvidos os estudos das potencialidades dos novos usos finais de eletricidade, vis-àvis outros energéticos, com a tradução desta potencialidade em requisitos de. energia elétrica e a inclusão destes requisitos no planejamento da expansão dos sistemas elétricos, o processo deverá ser iterativo entre o planejamento do Setor Elétrico e o do Setor Energético.

O planejamento macroeconômico foi muito esvaziado em relação ao seu próprio passado no país, em benefício de uma visão mais controladora do ponto de vista contábil-financeiro. Embora se possa esperar que, no curto prazo, com a unificação dos orçamentos na escala federal, a tendência não se inverta, acredita-se que o planejamento, a nível ma. cro, volte, em poucos anos, à merecida valorização.

Pode-se antever então que, a ambos os níveis, importantes reestruturaçōes deverão ocorrer, inclusive avultando a necessidade de uma certa convergência entre ambos (macro e setorial) com o planejamento da expansão do Setor Elétrico, se amoldando à nova configuração institucional para as atividades de planejamento.

\section{BIBLIOGRAFIA}

1. Documentos de Planejamento da ELETRO BRAS: CANAMBRA 1966, Power Mar ket Study and Forecast 1969, Revisăo do Balanço Energético 1972, Plano 90, 
Plano ENENORTE, Plano 95, Conjunto de Projetos Especiais da ELETROBRÁS, 1979, Plano 2000. Plano de Expansão Correspondente ao Programa de Recuperação Financeira do Setor Elétrico 1985

2. Documentos de Planejamento do GCPS Grupo Coordenador de Planejamento do Sistema Elétrico, especialmente o Boletim de Planejamento.

3. Metodologia de Planejamento do Sistema Elétrico - Trabalho apresentado ao SPISE-BRACIER 1985 - José Luiz AIqueres e outros.

4. Planejamento do Setor Elétrico - Conjun to de artigos apresentados nos Boletins de 1984 e 1985 da ABCE - Associação Brasileira de Concessionárias de Energia Elétrica e de autoria de António Carlos Tatit Holtz.

\section{A administração unificada das empresas de energia do Estado de São Paulo}

\section{JOSÉ GOLDEMBERG}

Reitor da Universidade de Sảo Paulo. Bacharel em Ciências pela USP e pos-graduado pela Universidade de Saskatcewan, Canadá. Foi presidente da CESP, CPFL, ELETROPAULO e COMGÁS.

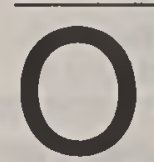

Governo do Estado de São Paulo detém o controle acionário de quatro empresas de energia. Destas, três são de energia elétrica: a CESP - Companhia Energética de São Paulo; a CPFL - Companhia Paulista de Força e Luze a ELETROPAULO - Ele tricidade de São Paulo S/A. - e uma de gás, a COMGAS Companhia de Gás de São Paulo. Esta última passou ao controle da CESP em novembro de 1984. Até então, era uma empresa do munićpio de São Paulo.

Além dessas três empresas de energia elétrica, atuam ainda em São Paulo dez outras, de pequeno porte, pertencentes à iniciativa privada. No entanto, cabem àquelas a responsabilidade pelo atendimento de $95 \%$ dos consumidores paulistas, que, por sua vez, consomem $97 \%$ da energia elétrica utilizada no Estado de São Paulo, conforme mostra a tabela.

Ainda com a intençẩo de mostrar ó tamanho e a importância das empresas de energia elétrica do Governo do Esta. do de São Paulo, gostaríamos de comparar a potência instalada e a produção da CESP lempresa geradora, supridora e fornecedoral com os valores do Brasil como um todo.

Em 1984, a capacidade geradora ins. talada da CESP, toda ela hidráulica, era de $8.468 \mathrm{MW}$ (outros 4.031 MW estavam em construçãol, valor que representava, na ocasiāo, perto de $24 \%$ da potência de geração hidráulica instalada no Brasil lou $20 \%$ do total brasileiro, quando se considera em conjunto a hidráulica mais a térmica).

Naquele ano, a produção da CESP totalizou 43,3 TWh (43,3 bilhöes de KWh), valor que representou cerca de $25 \%$ de toda energia elétrica produzida no Brasil.

Desde março de 1983, as empresas de energia elétrica passaram a ter Administração Unificada, ou seja, um só Presidente e um só Conselho de Administra- ção para todas elas. Hoje, entre elas está incluída a COMGÁS.

Por que uma Administração Unificada? Por que não uma Secretaria de Estado? Por que não uma empresa "holding", nos moldes da ELETROBRÁS? ou, ainda, por que não fusioná-las? Estas e muitas ou tras interrogaçōes foram colocadas às equipes que, neste campo, assessoravam o candidato eleito para governar São Paulo. Todas as possibilidades foram es estudadas com o máximo de cuidado.

A proposta escolhida foi a da Administração Unificada e com ela pôde o Governo assegurar unidade de comando a todo o complexo energético do Estado, concedendo, inclusive, o status de Secretário de Estado ao Presidente das empresas. Com isso, as trés empresas passaram a trabalhar de maneira integrada, inclusive no que diz respeito à otimização dos recursos disponíveis, man. tidas as características próprias de cada uma e sempre visando ao objetivo comum e prioritário que é atender, o mais eficazmente possivel, aos interesses do povo paulista.

A manutençāo das características próprias de cada uma das empresas tornou-se extremamente importante, pois na forma de agir, a experiência vem sendo acumulada, como no caso da CPFL e da ELETROPAULO, por perfodo superior a sete décadas.

Logo no in ício do Governo Montoro, foi criado o Conselho Estadual de Energia, integrado por representantes do Governo, do empresariado, das Universidades e dos trabalhadores, com a função precipua de traçar a política energética global no Estado de São Paulo.

\section{Os problemas iniciais}

De infcio, a Administração Unificada encontrou uma série de dificuldades decorrentes da conjuntura adversa que atingia toda a economia brasileira: uma forte recessão unida a uma alta taxa de inflação, que infelizmente ainda permanece; um endividamento externo, cujo montante atingia indices insustentáve is e, ainda, a reduçāo da atividade indus trial, que trouxe ao setor elétrico, em particular para as empresas de São Pau. lo, conseqüências de duas ordens: a que. da acentuada das taxas de crescimento 